\title{
The Effect of Risk and Uncertainty Factors on Managerial Decision Making
}

\author{
Mian Numan Raheem, M. Adrees \\ University of Education Lahore, Pakistan \\ miannumanraheem@gmail.com, adrees.aadi@gmail.com
}

\begin{abstract}
This study evaluated the effect of risk and uncertainty factors on financial decision making. The long-term goals and ways for achievement are constantly attached with uncertainty since we don't know the circumstances, either positive or negative, which happen later. Uncertainty is a key logical factor that influences the dynamic. The reason for this investigation is to check how risk and factors of uncertainty impact the financial aspects of a firm. The risk factors incorporate, financial risk, market fluctuations hazards, fluctuation of unfamiliar and loan costs. Uncertainty factors incorporate political, monetary and environmental uncertainty. The results reveal that management knowledge and expertise related to these factors are utmost important for effective decision making and sustainable growth.
\end{abstract}

Keywords: Financial Risk, Market Fluctuations Hazard, Political, Monetary, Uncertainty

\section{Introduction}

Evidence whether firms with higher risk pick a more straightforward or more obscure risk detailing system in their annual reports is blended (Monjed \& Ibrahim, 2020, Myšková \& Doupalová, 2015). A possible clarification is organizations pick the elective announcing system to risk disclosure (RD), to be specific pay smoothing (IS), given organizations with smarter pay are looked at as being safer (Graham et al., 2005). Securities exchanges have been at the focal point of economies for quite a long time. Any insecurities or emergencies happening in these business sectors have fractional or general impacts on the economy. Since the seventeenth century, the world economy experienced numerous emergencies that emerged from monetary and all the more explicitly, stock trade markets (Demir, 2019). Of late, the worldwide monetary emergency of 2008 which emerged from the US economy-influenced numerous nations. Nonetheless, the 2008 monetary emergency just somewhat influenced the Turkish economy contrasted with the US and mainland Europe. Swelling rate is the Granger reason for stock returns just in Argentina and Brazil; financing cost is the Granger cause for stock returns in, Brazil, Argentina, Pakistan and also Zimbabwe; conversion scale is the Granger reason for stock income just in Brazil, Greece, Korea, Colombia, Mexico and Nigeria; the SP500 file is the Granger basis for stock incomes in Colombia, Mexico and Portugal. Modern creation doesn't affect the stock income in any of Nineteen Nations.

Despite this, chiefs additionally will in general acknowledge less Risk since high Risk can prompt monetary emergencies, risking directors' security work. Be that as it may, risk avoidance can likewise prompt an absence of venture openings with high risk, which lessens organizations' worth (Salehi et al., 2020). Thus, corporate chiefs need to settle on objective choices about corporate Risk-taking to prevail in the serious financial world to urge financial backers to put resources into their organizations. Then again, narcissism is related proudly, prevalence and appreciation in individuals (Salehi et al., 2020). The developing admittance to new computerized advancements in assembling organizations has set out open doors for computerized advancement (Johansson et al., 2020). Move to value has been concentrated widely with not a single complete conclusion to be seen. The just end that can be affirmed is that various methodologies are introduced relying upon a large group of conditions (Smolarski et al., 2019). Together these progressions have brought about a central rebuilding of firms with uplifted execution tension on supervisors at all levels; and, therefore, those equivalent chiefs have seen their professional stability reduce. Directors' previous insusceptibility from monetary changes and practically ensured versatility inside regulatory firms has been supplanted by lay-offs and a redefinition of their vocation stepping stools (Breckenridge \& Taplin, 2009).

The causalities among the choice of macroeconomic factors and the securities exchange value list, for example, net public item, the record of purchaser value, supply of cash, money cost and trade-off scale. The examination was mainly centered on the ASEAN-5 Nations (Malaysia, Philippines, Singapore, Indonesia and $5^{\text {th }}$ one Thailand) over the period of1985-1996. They find out that all the components are huge determinants of microeconomics in the securities exchange file in these nations. Hajilee and Al Nasser (2014) find the 
linkage between financial exchange improvement and trade rates in twelve arising economies over the 19802010 periods. Their outcomes showed that in just six economies, huge since quite a just ago runs links are marked. As it is indicated by the searches, substitution scale instability adversely influenced securities exchange improvement in Pakistan, Venezuela, China and Mexico, and also positive effects were found in the Philippines and South Africa.

The absolute most compelling researchers have distinguished uncertainty as to the reason of the managerial cycle, prompting authoritative reactions that support their specialized center from this ecological uncertainty (Noy \& Ellis, 2003). Even though each progressive age of administrators has needed to confront more prominent measures of natural uncertainty than their archetypes, it is neglectful to accept that the uncertainty facing the current age is of a similar structure and simply more unique. Early conversations about uncertainty might follow back to the disclosure of indeterminacy of a bolt-in trip by Hellenistic rationalist Zeno in the $5^{\text {th }}$ century BC (Noy\& Ellis, 2003). From that point forward, the very development of uncertainty has advanced in the manner that individuals have perceived and experienced it. The essential test before associations and their chairmen since the beginning has been the need to adapt to uncertainty about what's to come. Associated with this test has been the expanding center around and different meanings of uncertainty. Researchers, for example, Knipes \& Gauthier (2012) managed uncertainty inside the system of financial aspects, explicitly tending to how uncertainty prompts value variances.

In any case, in this period the presence of uncertainty in business writing was conflicting and rare. Knight (1921) in this book about risk, uncertainty and profit gives first inside and out treatment of uncertainty in business writing. Knight outlined thoughts of Risk (quantifiable uncertainty) uncertainty (immense in his "actual" structure). Knight attested that uncertainty turns the idea of dynamic as an errand of choosing what has to do and how has to do it outweighs that of implementation. Although hazard-taking conduct is a generally explored point in the account, an inquiry of exact writing shows that shopper dynamic exploration with regards to monetary items is shockingly scant (Hamid et al., 2013). Past exploration on risk dynamics has concentrated on individual risktaking conduct in a hierarchical setting particularly in administration dynamics. There is a lack of dynamic investigations with regards to the protection market by and large and none exists from an arising economy specifically. In that capacity, this paper tries to address a gap in literature. There exists a wealth of literature in administration and activities research that talks about risk (Zsidisin et al., 2000). However, there is a restricted examination that has expressly considered risk appraisals, emergency courses of action, and risks the executives inside the setting of inbound stock. The accompanying segment will talk about the writing-related with supply hazard, give an illustration of a firm that epitomizes some stock risks that exist and momentarily depict chance evaluations and risk the executives.

\section{Literature Review}

The connection between Risk and Uncertainty: Researchers, for example Knipes \& Gauthier (2012) managed uncertainty inside the structure of financial aspects, explicitly tending to how uncertainty prompts value variances. Notwithstanding, in this era, the existence of uncertainty in business writing was irregular and also rare. Apparently, Knight (1921) in his book Risk, Uncertainty and Profit gives the first top to the bottom treatment of uncertainty in business writing. Knight divided the ideas of Risk (quantifiable uncertainty) with doubt (immense in its "actual" structure). In the most recent years, there has been an expanding interest in the part of effect in decision-making under exposure. Paul Slovic and his associates have built up a hypothesis about the purported 'influence heuristic': full of feeling reactions to an enormous degree decide our decisions about Risk (Roeser, 2010). Knight attested that uncertainty turns the idea of dynamic as the errand of choosing what we have to do and how to do it outweighs implementation. Ashby (1958), in the field of robotics it was through his Law of necessary diversity, showed that alluring results despite aggravations could happen if the controller had the vital assortment of reactions. Penrose (1995) manages the test of risk and uncertainty, in her original work the theory of Growth of the Firm. She separates between the two by noticing thatambiguitysuggest to the business person's trust his/her assessments and assumptions; at the same time as a hazard, alludes to the potential results of activity, explicitly to misfortune it may be caused if a certain move is made. She more expresses that the more prominent the Risk or uncertainty, the extra troublesome the administrative undertaking will be. She with the aim of point infers 
that the development policy of a firm be essentially confined by the limit of the board to manage the expanded issues by which they are stood up to. In this manner, uncertainty and Risk go about as restricting components on extension for some random degree of experienced administrative administrations numerous systems of government in Nigeria have consistently received expansionary monetary strategy with the target of guaranteeing that the normal Nigeria specialist is all around provided food for. The Udoji Award of 1976 and other government assistance bundles to laborers have been ascribed to as the first reasons for expansion and joblessness in Nigeria (Igwe, 2016).

Difference between Risk and Uncertainty: While a few scientists place the differentiation among risk and uncertainty regarding the presence (or else not) of abstract chances (Holanda et al., 2018). This qualification lays resting on the presence of target chances. The thinking comes from Knight's (1921) understanding with the aim of if "an uncertainty be capable of being diminished to a goal, likelihood, it preserved to be decreased to finish assurance via gathering the cases" (p. 231). For Leroy and Singell, Knight's risk circumstances suggest the insurable risks, whereas uncertainty is related to certain perils. Starting here of view, the distinction between uncertainty and risk gets zeroed in on a trait of the real world (Holanda et al., 2018).

Uncertainty: Uncertainty is a difficult term; it is the subject of study across various controls and, thusly, needs normal binding together qualities (Ulibarri, 2019). The Oxford English Dictionary characterizes uncertainty, fairly repetitiously, as "the nature of being dubious in regard of span, continuation, event, and so on; risk to the possibility or mishap ... the nature of being vague as to greatness or worth. The condition of not being unquestionably known or clear; suspiciousness or ambiguity." At its generally fundamental, uncertainty is accordingly a nonappearance of information about a subject (Ulibarri, 2019). Much consideration goes toward lessening logical uncertainty, into attempting to more readily show or foresee the connection between pertinent segments in a framework: If we increment stream streams, will this expansion salmon territory? An absence of information may likewise emerge about the principles and guidelines that shape what chiefs can do, known as managerial or institutional uncertainty (Ulibarri, 2019).

\section{Dimensions of Uncertainty}

Subjective uncertainty: is the perspective of a business visionary, together with emotional appraisals of the risks of frustration. Penrose's (1995) answers for assuming the test of abstract uncertainty is to put more assets in "administrative exploration. The abstract idea of the apparent uncertainty started to get more noteworthy consideration in the association conduct writing for the duration of this period (Knipes \& Gauthier, 2012). One of the principal experimental investigations lying on the emotional idea of authoritative uncertainty next to two measurements. $1^{\text {st }}$ measurement was secured by means of the elements to be careful inside Uncertainty in administration 205 choice units that went as of easy to difficult. Other measurements were secured through the change in the elements, which went from fixed to active. Causative experimental verification to prior episodic thoughts. Duncan (1972) arrived at resolution with the aim of uncertainty and the level of unpredictability ought not to be measured as steady highlights in association accept instead as reliant on the view of association individuals. Emergency inclined pioneers are exemplified by centralization, pomposity (Richardson, 1993) and risk-taking (Watkins and Bazerman, 2003), by and large inferring a valuebased style. Presumptuousness and neurotic inclinations in this vein upset beset administrators' judgment (Bar-Joseph and Sheaffer, 1998).

A few different investigations have coordinated consideration on how industry uncertainty. Effects in support of instance. Elango and Sambharya (2004) initiated the opposition also request uncertainty significantly affect MNCs' entrance mode choices. Dark (1994) puts more spotlight on innovative uncertainty within MNCs' opening method choices. along with the various elements of uncertainty within the firm uncertainty classification, MNC's experience has pulled during the best exploration consideration and be extensively perceived as affecting an MNCs' recognizable proof and view of different elements of uncertainty, section mode decision choices (Sniazhko, 2019).

Effect of uncertainty Factors on decision making in Business: Uncertainty and its part in dynamic is a significant marvel that has gotten impressive examination consideration inside the worldwide business (IB) concentrates in the course of the most recent fifty years. Uncertainty, characterized as the absence of 
information about the probabilities of things to come condition of occasions. Knipes \& Gauthier (2012) have been appeared to influence global companies' (MNCs) rate of worldwide development, their globalization ways, section method decisions, and level of responsibility (e.g., Musteen, 2011; Johanson and Vahlne, 1977; and Liesch, Welch, Aharoni, 1966; Aharoni, Tihanyi, and Connelly, 2011; Ahsan and Buckley, 2011). The powerlessness of a chief to dispose of uncertainty obliges the viability of dynamic and needs a selection of techniques also help to lessen, or in adaption to uncertainty. Late examinations regularly separate among exogenous and endogenous uncertainty, just as natural, industry, along firm uncertainty. likewise support the persevering administration of uncertainty to develop the odds of MNCs getting by in the global industry climate (Sniazhko, 2019).

Despite the fact that uncertainty has been joined into numerous examinations on dynamics inside MNCs, the IB writing needs away from between various elements of uncertainty and regularly treats the idea conflictingly. Examination recognizes ecological and firm uncertainty, yet the measurements used to catch such uncertainty fluctuate altogether among contemplates. This irregularity is tricky because it gives clashing outcomes in relation to MNCs' decision-making below uncertainty, obstructs information advancement with methodical management of the uncertainty, and shows an inadequate image of jobs uncertainty acting inside worldwide dynamic. As far as training, the absence of away from among various components of uncertainty may bring about misdirecting impression of the genuine climate and therefore to hazardous and uncalled-for choices (Sniazhko, 2019). Risk in creative writing has generally been dissected under (I) yield value weakness and (ii) creation weakness (usually known as supportive of diction hazard). Yield cost can be uncertain because of an assortment of reasons. Perhaps the main factor is the presence of a delay between the utilization of data sources and the yield sold (Kumbhakar, 2002).

Uncertainty management: According to Sniazhko (2019) methodologies MNCs relate while overseeing uncertainty the board systems were utilized as a beginning point. All the additional explicitly, in survey joins two uncertainty the executives' strategic uncertainty decrease (alluded to like "monetary Risk" the board by Miller), Uncertainty adapting (alluded to the same as "essential administration" by Miller). Uncertainty decrease limits an MNC's sincerity to specific uncertainty not including changing the company's technique (Miller, 1992). Uncertainty decrease is characteristic, essential helper also central need to direct MNCs' conduct (Beckman, Haunschild, and Phillips, 2004; Mullin and Hogg, 1998). Uncertainty adapting, then again, affects the MNC's openness across a broad range of uncertainty in addition to sometimes wanting the MNC to change its methodology (Miller, 1992). Although two ideas are equivalent in the two structures, Simangunsong et al. (2012) phrasing from the time when the evaluated IB writing regularly suggests to uncertainty the executives as far as to decrease and adapting instead of monetary and key Risk the board. The financial turn of events and development are the principle objectives that all nations should think about in creating public methodologies. The monetary emergency began in 2007 in the United States and has influenced EU nations in under a year, 2008 and 2009 speaking to a troublesome period when economies and funds of Member States were influenced. After a slight improvement in 2010, the skeptical situations of business analysts with respect to the tirelessness of the downturn have gotten valid. Blyth (2013) noticed that new improvements in the sovereign obligation emergency is a consequence of the monetary emergency, as governments have mediated to save the financial areas and, along these lines, the monetary emergency has transformed into an obligation emergency. The entirety of this prompted an expansion in monetary Risks that have influenced financial development. The development of aggravations referenced above developed the monetary framework weakness and the entire framework got inclined to stuns.

Subsequently, most importantly, a few macroeconomic speculations pointing at firms' hazard avoidance will be investigated (Salman \& Fuchs, 2015). Hence, the outcomes of these discoveries are inspected (Levi, 2014). A first and most evident clarification which proves the suspicion on risk loath firms follows back to blemishes in the value market. While in customary Keynesian hypothesis no differentiation is made whether a company's financing base is gotten from value markets or obligation markets (Fletcher, 1989). This is a focal issue for New Keynesian business analysts (Mankiw and Romer, 1991a; Mankiw and Romer, 1991b). Also stochastic, genuinely unusual uncertainty for example sudden changes of government, enormous scope natural aggravations, or war, can influence the setting wherein dynamic happens (Ulibarri, 2019) and uncover a set-up of new unanswered inquiries (Ulibarri, 2019). These uncertainties can influence the quality and results of dynamic uncertainty lead individuals to settle on unreasonable choices (Holanda et al., 2018), 
and support narrow-minded conduct (Barrett and Dannenberg 2014). In addition, people see Risk and uncertainty in an unexpected way, which can prompt miscommunication, insufficient positioning of qualities, and incapable treatment of natural issues Nonetheless uncertainty are not consistently adverse to dynamic, since they give a chance to supervisors to learn and improve (Ulibarri, 2019).

Risk: Risk is the level of uncertainty related to the potential results as a choice (Holanda et al., 2018). Risk is natural during practically all production exercises. Numerous administrators accept they give close consideration to the Risks, in any case, particularly in independent ventures the Risks are checked unsystematically, at arbitrary, instinctively and casually. Frequently, the dominating conviction is that the administration or the proprietor knows well all potential Risks, so there is no compelling reason to manage them independently. Another The Authors trap is the checking of Risks with just barely characterized rules, which can prompt one-sided results and mistaken administrative choices (see Alquier and Tignol, 2006). For instance: the basic issue, which incredibly influences the dynamics of the venture, is to distinguish expected cost reserve funds (Myšková \& Doupalová, 2015). Another misguided judgment is that the term hazard the executives alludes just to intercessions, or therapeutic estimates that are taken because of the signs of Risks.

Around a similar time as the Rosenberg audit, natural and asset financial experts started to get a few relevant ideas as of the field of money, specifically, to vulnerability about the future estimation of endeavor and its ruined expenses give an elective clarification to speculation slacks (Arrow and Fisher, 1974). A push of the exploration was to prove with the aim of there is a choice benefit of holding on to contribute while there is vulnerability regarding the future settlements and their sunk expenses as in individual can't recover all speculation expenses while disinvesting (additionally called the level of irrecoverability of the venture). progression of documents within the financial matters writing built up these thoughts at the same time as they apply to the speculation choices of extractive businesses (Marra et al., 2003). In recent times has a line of requests are applied to agrarian venture issues (Marra et al., 2003). Chavas contends to, due to sunk costs, it could be publicly ideal for governments-if value floors to lessen the vulnerability of venture. Purvis et al. applied plan to dairy rancher interest in new ravage administration innovation and find to, contrasted with the net present worth way to deal with the speculation choice, the choice worth methodology inferred a fundamentally higher revenue stream was needed before venture would occur. Zhao, utilizing a gamehypothetical methodology, considered the situation where the alternative benefit of holding back to receive is identified with the chance to notice prior adopters' involvement in the innovation.

The Risk for botch hosts has been set upon the get-together committing an error and the reasoning being that such a standard makes a motivating force to act cautiously and dodge botches from being imparted. These perils are moreover affected by diverse qualities of information systems, particularly the ease of utilizing of UIs (Center, 2009) interests, the exterior perils commonly can't be controlled or directed - these are, for occurrence, macroeconomic threats. (Myšková \& Doupalová, 2015), regardless, proposes that the closer the commerce climate is to the internal one, it is less complex to affect it. At long last, there is the supposition that the center of democratization is appropriately public; that majority rule government at the level of each country state will create a general vote-based system. Against this, it very well may be called attention to that globalization has increased to the stage where the public vote-based government can't create an all-inclusive vote-based system, on the off chance that it actually might have done as such. Democratization should incorporate endeavors to carry majority rules system to different focuses of dynamic too (Law, 2003).

Classification of Risk: For the foremost portion, Risks are isolated into considerable and tricky, controllable and wild, insurable and uninsurable or, with respect to the degree of energy, into key, vital and operational. Regularly they are moreover confined to money-related and non-monetary Risks. Concurring to the subject who bears the chance, we are able to recognize inward and exterior risks. Uncommon endeavors to genuinely explore exactly the parts of risk with uncertainty in reception incorporate investigations by According to (Marra et al., 2003). Significantly less investigation about risk and selection include utilized straight meeting methods to examine the impact of ranchers' risk perspectives and impression of the riskiness of a venture lying on the placements of choices. In any case, except for Marra et al., (2003) these examinations have commonly had low logical force. Exploration on the monetary risk coming about because of financing choices is frequently estimated unbiasedly utilizing assessments of the costs and the capital structure. Speculation risk examination alludes to the feasibility of ventures, and inside this specific circumstance, risk investigators 
have created appraisal procedures that have developed from old style deterministic models to probabilistic methods.

Drawing on the social choice hypothesis also on Santacruz (2019a) meanings of risk as well as uncertainty, this investigation tends to two inquiries according to the advancement of an administrative stage dynamic system. To start with, how might the factors and ideas related to risk-taking exist characterized inside the setting of chief risk-taking, and next, what is the relationship between ideas recognized to impact dynamic on the director level in the corporate settings? The commitment of the current investigation is the introduction of staggered sculpts as to can be utilized to give setting to how supervisors think about business destinations and measure perspectives identified with the goals of associations, thinking about a company's capacity to ingest potential misfortunes. The cutting edge beginning of the understanding of risk dates to Knight's (1921) meanings of risk also uncertainty. Knight recognized the risk from uncertainty, assigning the previous like"quantifiable uncertainty," also as "immense uncertainty." therefore, the discussion on the occurrence of the prejudice on the evaluation of probabilities gets as of Knight's dispute with the aim of uncertainty emerges as leaders gauge the risks of disappointment or achievement dependent at remarkable analytics. (Zhang, 2018). The exclusivity of business choices identifies with the job suppositions taken without evenness or homogeneous information. This comes after Knight's perception to dispassionately estimated chances infrequently falls with regards to everyday company questions. This infers that but the probability of progress or disappointment isn't straightforwardly quantifiable before a choice is made, the risk can't be killed. All things considered, chiefs should endeavor to alleviate negative choice results. The writing is also a risk in itself. The writing cautions that there is an underlying propensity to exaggerate benefits and that the providers are probably going to perform better in the start of an agreement to establish great first connections. Santacruz (2019b)discusses various risks related to reevaluating. Since rethinking is a fairly late device of chiefs the total expenses are not yet known, which groups.

Positive and Negative Sides of Risk: The essential gathering of definitions zeros in the fair on the negative side of chance, where the hazard is seen as a threat. For instance, Myšková \& Doupalová (2015) typify risk like a dread of the likely unmistakable and theoretical effect of the dubious climate on accomplishing the objectives set. Myšková \& Doupalová (2015) suggest risking as possible negative deviations from the objectives set. The essential gathering of definitions zeros is fair on the negative side of chance, where the hazard is seen as a threat simultaneous with the predominance of emergencies, ascendance of ladies to higher administrative echelons is additionally getting regularizing in business and non-benefit associations (Sheaffer et al., 2011). Monetary Risks emerge from the probability of bringing about monetary expenses because of the speculations put in organizations that are in default on their monetary commitments.

Hence, public governments have ensured for the financial area obligation through government securities, to save the area, since some credit organizations were too imperative to possibly be left to fall flat. Hence, bank obligation was changed over into public obligation and undeniable degrees of it have prompted extra monetary Risks (Jianu, 2017). In most agricultural nations, governments, advancement offices, and private sec peaks perceive the part of destitution decrease and food security and, accordingly, are increasingly putting resources into horticultural worth chains, giving information sources, financing, and different administrations that help their turn of events. In the course of recent many years, food accessibility has been enormously improved through profitability gains in the rural area (Linn \& Maenhout, 2019). This has occurred despite the way that the level of ladies diminishes bit by bit however strongly towards the most noteworthy echelons (Sheaffer et al., 2011). At that point once more, potential deviations from the typical result may moreover take a charming heading, which may be a more broad thought of chance. This moment gathering of implications of risks centers on characterizing risks as distant as conceivable chances. Myšková \& Doupalová (2015) for the occasion characterizes the response to a chance as a response to a possibility, through these choices: recognize, share, brace or utilize the chance.

As per Krishtaleva et al. (2020) in any case, by and by more thought is given to the negative deviations, which depend on the standard of reasonability. Risk is thusly viewed as regarding a few substitute arrangements when one of the alternatives is generally annoying. The risk would thus be able to be depicted as an element of two factors, the likelihood of an event and the possible effect of a specific occasion. Individuals may in challenges increment risk-taking since they see that the contenders are less gifted or fortunate (Gärling et al., 2020). Gärling et al. (2020) suggest that in risk-taking competitions social examination is unsafe to an 
influenced thinking preference of being more talented than the contenders which initiate pomposity bringing about expanded risk-taking. Keeping away from risk ought to in resource markets be liked to facing challenge if a protected choice (not contributing) is bound to be advantageous and the converse if a risky alternative (contributing) is bound to be helpful. The unforeseen dynamic system places that risk inclination and hence the risk-return relationship could change contingent upon the setting of the decision. Reference-based models of decision under this structure accept that organizations choose their risk inclinations in the wake of contrasting their presentation with certain reference focuses. The most unmistakable model, prospect hypothesis expresses that people are risk opposed when possibilities are positive and risk looking for when possibilities are adverse. Hamid et al. (2013) renders to a situational outlining where great execution by the firm is related to risk repugnance and terrible showing by the firm is related with risk looking for conduct. The quick-changing climate and firms' confounded operational techniques together add to a more elevated level of inventory network chances (Shou et al., 2018).

\section{Conclusion}

In this study, we discuss the effect of uncertainty and risk on managerial economics. Uncertainty factors like political and market uncertainty affect the decision making and market uncertainty affects the investors to invest in markets like stock markets which are very important for a country to grow. The second factor is risk which affects the operations of any organization and also of the country. Financial risk is the most common risk born by an economy it affects the most decisions and important work of the country. Due to less information managers did not do the right things and they make wrong decisions, they are not able to handle the risky conditions because they don't follow the rules of organizations. Managers should be flexible while facing any uncertain Situation. If these factors are not controlled by managers then it can be very risky for the firm or business. These factors have the power to run the economy of any nation because once they get out of control then it is very difficult to control them. The proper analysis of problems should be done and some information technology tools should be used to solve them out.

\section{References}

Breckenridge, S. R. \& Taplin, I. M. (2009). Managerial uncertainty as a feature of organizational form: A sociological perspective. Journal of Business and Industrial Marketing, 24(7), 487-495.

Demir, C. (2019). Macroeconomic Determinants of Stock Market Fluctuations : The Case of BIST-100.7(1).

Gärling, T., Fang, D., Holmen, M. \& Michaelsen, P. (2020). Financial risk-taking related to individual risk preference, social comparison and competition. Review of Behavioral Finance, ahead-of-p (ahead-ofprint).

Hamid, F. S., Rangel, G. J., Taib, F. M. \& Thurasamy, R. (2013). The relationship between risk propensity, risk perception and risk-taking behavior in an emerging market. International Journal of Banking and Finance, 10(1), 134-146.

Holanda, L., Nobre, N., Grable, J. E., Vieira, W. \& Pq, B. P. (2018). Managerial risk-taking : a conceptual model for business use. Management Decision, 56(11), 2487-2501.

Igwe, A. (2016). Impact of fiscal policy variables on economic growth in Nigeria ( 1970-2012): a managerial economics perspective. Investment Management and Financial Innovations, 12(2), 169-179.

Jianu, I. (2017). the impact of financial risks on economic growth in EU-15. Theoretical and Applied Economics, XXIV(1), 23-44.

Johansson, S., Kullström, M., Björk, J., Karlsson, A. \& Nilsson, S. (2020). Digital production innovation projects - The applicability of managerial controls under high levels of complexity and uncertainty. Journal of Manufacturing Technology Management, ahead-of-print, (ahead-of-print).

Knipes, B. \& Gauthier, J. (2012). Antecedents and implications of uncertainty in management. Management History, 18(2), 200-218.

Krishtaleva, T. I., Gureeva, E. A. \& Rykova, I. N. (2020). Risk-oriented approach to managing the social market economy. International Journal of Sociology and Social Policy.

Kumbhakar, S. C. (2002). Empirical Risk preference and productivity measurement under output price uncertainty. Empirical Economics, 27(3), 461-472.

Law, M. (2003). MNEs, Globalisation and Digital Economy: Legal and Economic Aspects by Dr. Georgios I Zekos. Managerial Law, 45(1/2), 1-12. 
Linn, T. \& Maenhout, B. (2019). The impact of environmental uncertainty on the performance of the rice supply chain in the Ayeyarwaddy Region, Myanmar. Agricultural and Food Economics, 7(1), 1-29.

Marra, M., Pannell, D. J. \& Abadi Ghadim, A. (2003). The economics of risk, uncertainty and learning in the adoption of new agricultural technologies: where are we on the learning curve. Agricultural Systems, 75(2-3), 215-234.

Monjed, H. \& Ibrahim, S. (2020). Risk disclosure, income smoothing and firm risk smoothing. Journal of Applied Accounting Research, 21(3), 517-533.

Myšková, R. \& Doupalová, V. (2015). Approach to Risk Management Decision-Making in the Small Business. Economics and Finance, 34(15), 329-336.

Noy, E. \& Ellis, S. (2003). Risk: A neglected component of strategy formulation. In Journal of Managerial Psychology, 18(7-8),691-707.

Roeser, S. (2010). Intuitions, emotions and gut reactions in decisions about risks : towards a different interpretation of ' neuroethics .' Journal of Risk Research, 13(2), 175-190.

Salehi, M., Afzal Aghaei Naeini, A. \& Rouhi, S. (2020). The relationship between managers' narcissism and overconfidence in corporate risk-taking. TQM Journal, 2015.

Salman, A. K. \& Fuchs, M. (2015). Assessing risk factors of business failure in the manufacturing sector : a count data approach from Sweden. International Journal of Economics, Commerce and Management, United Kingdom, III(9), 42-62.

Santacruz, L. (2019a). Measures of firm risk-taking: revisiting Bowman's paradox. Managerial Finance, 46(3), 421-434.

Santacruz, L. (2019b). Measures of firm risk-taking: revisiting Bowman's paradox. Managerial Finance, 46(3), 421-434. https://doi.org/10.1108/MF-09-2019-0466

Sheaffer, Z., Sarfaty, S., Group, P. \& Aviv, T. (2011). Leadership attributes, masculinity and risk-taking as predictors of crisis proneness. Gender in Management: An International Journal, 26(2), 163-187.

Shou, Y., Hu, W., Kang, M. \& Park, Y. W. (2018). Risk management and firm performance : the moderating role of supplier integration. Industrial Management and Data Systems, 118(7), 1327-1344.

Smolarski, J. M., Wilner, N. \& Vega, J. G. (2019). Dynamic transfer pricing under conditions of uncertainty - the use of real options. Journal of Accounting and Organizational Change, 15(4), 535-556.

Sniazhko, S. (2019). Uncertainty in decision-making: A review of the international business literature Uncertainty in decision-making : A review of the international business literature. Cogent Business \& Management, 6(01). https://doi.org/10.1080/23311975.2019.1650692

Ulibarri, N. (2019). Collaborative governance: a tool to manage scientific, administrative, and strategic uncertainties in environmental management? Ecology and Society, 24(2).

Zhang, L. (2018). Procurement risk management under uncertainty : a review. Industrial Management \& Data Systems, 118(7), 1547-1574.

Zsidisin, G. A., Panelli, A. \& Upton, R. (2000). Purchasing organization involvement in risk assessments, contingency plans, and risk management: an exploratory study. Supply Chain Management, 5(4), 187-197. 